\title{
InTeração entre Tamanhos de Vaso e Doses de Glyphosate no CONTROLE DE BRAQUiáRIA ${ }^{1}$
}

\author{
Pot Size and Glyphosate Dose Interactions on the Control of Suriname Grass
}

\author{
CAMPOS, A.A.V. ${ }^{2}$ e RONCHI, C.P. ${ }^{2}$
}

\begin{abstract}
RESUMO - Objetivou-se com este trabalho avaliar a interação entre o tamanho do vaso de cultivo e doses de glyphosate no crescimento, na fisiologia e na eficácia de controle de Brachiaria decumbens. A semeadura foi feita em vasos contendo 2, 5, 10 e $20 \mathrm{~L}$ de substrato, mantidos em casa de vegetação. Entre os 41 e 63 dias após a emergência (DAE), avaliou-se o crescimento de $B$. decumbens. Aos 64 DAE, fez-se a aplicação do glyphosate nas doses de $0,0,0,8,1,6$ e 3,2 $\mathrm{kg} \mathrm{ha}^{-1}$ de equivalente ácido. Foram avaliadas as trocas gasosas e a fluorescência da clorofila $a$, aos dois dias após a aplicação (DAA), bem como a eficácia de controle, aos 7, 14, 21 e 28 DAA, sendo nesta última avaliação determinada ainda a matéria seca da parte aérea. Por fim, aferiu-se ainda a capacidade de rebrota de $B$. decunbens aos 28 dias após o corte. O crescimento de $B$. decumbens aumentou linearmente com o aumento do tamanho do vaso. As trocas gasosas e os parâmetros de fluorescência foram afetados pelas doses de glyphosate, mas não pela variação do tamanho do vaso. Não houve interação significativa entre doses e tamanhos de vasos sobre a eficácia de controle, porém essa variável aumentou consideravelmente com o aumento da dose e, discretamente, com o aumento do tamanho de vaso, sobretudo nas avaliações até os 14 DAA. A matéria seca da parte área aos 28 DAA e de rebrota foi dependente da interação entre tamanho do vaso e dose de glyphosate. O tamanho do vaso deve ser escolhido com critério para ensaios de eficácia de controle de $B$. decumbens com herbicida sistêmico.
\end{abstract}

Palavras-chave: Brachiaria decumbens, fotossíntese, herbicida, plantas daninhas, restrição radicular.

\begin{abstract}
The aim of this work was to evaluate pot size and glyphosate rate interaction on the growth, physiology and control of Brachiaria decumbens weed. It was sowed in 2, 5, 10 and 20 L-pots, which were kept in greenhouse. Plant growth was assessed from 41 to 63 days after plant emergence (DAE). Glyphosate was applied to all pot sizes at 0.0, 0.8, 1.6 and $3.2 \mathrm{~kg} \mathrm{ha}^{-1}$, at 64 DAE. Leaf gas exchange was assessed along with chlorophyll fluorescence at two days after application (DAA); weed control level at 7, 14, 21 and 28 DAA; weed dry matter at 28 DAA; and weed sprouting dry matter at 28 days after weed cutting. B. decumbens growth increased linearly with increased pot size. Both weed gas exchange and chlorophyll fluorescence parameters were affected by glyphosate rates, but not by pot size. No significant interaction between glyphosate doses and pot size on weed control levels was found, but it increased strongly with increasing herbicide rates and only slightly with pot size, particularly up to 14 DAA. Weed dry matter at $28 \mathrm{DAA}$ and plant regrowth differed according to pot size and glyphosate dose interaction. It was concluded that pot size should be precisely chosen to test systemic herbicide efficacy on the control of B. decumbens.
\end{abstract}

Keywords: Brachiaria decumbens, herbicide, photosynthesis, root restriction, weed.

Recebido para publicação em 8.4.2015 e aprovado em 3.7.2015.

2 Universidade Federal de Viçosa, Campus Florestal, Florestal-MG, Brasil, <alissonavcampos@yahoo.com.br >. 


\section{INTRODUÇÃO}

Muitos experimentos, nas diversas áreas do conhecimento, são conduzidos em condições controladas, onde as plantas são cultivadas em vasos com pequeno volume de substrato. Apesar de a escolha do tamanho do vaso de cultivo ser parte integrante de qualquer projeto de pesquisa com plantas, o tamanho dele é, geralmente, ignorado pelos pesquisadores. Muitas vezes ele é escolhido em função da conveniência ou apenas da disponibilidade no centro de pesquisa, quando deveria ser definido com critério, em função principalmente das características morfológicas da espécie e do tempo em que se pretende manter tal espécie nesses vasos, para as avaliações necessárias aos objetivos propostos (Ronchi et al., 2006; Almeida et al., 2014).

A sincronização entre a demanda do dreno (raízes) e a capacidade fotossintética da fonte (folhas ou parte aérea como um todo) é de fundamental importância para o crescimento da planta (Stitt, 1991), sobretudo da parte aérea. Com efeito, diversos estudos com plantas em vasos têm mostrado que a redução no crescimento da parte aérea está associada à limitação do crescimento do sistema radicular dessas plantas (Ronchi et al., 2006; Vallone et al., 2010; Santos et al., 2012; Almeida et al., 2014). Vale ressaltar que na parte aérea estão localizados os órgãos nos quais quase sempre são feitas as medições ou coletas para análises diversas dos experimentos com plantas. Assim, os resultados obtidos em vasos de pequena capacidade podem frequentemente ter pouca aplicabilidade ou mesmo induzir o pesquisador a conclusões parcial ou completamente diferentes daquelas que seriam obtidas caso ele tivesse optado por um vaso de maior capacidade, ou caso ele tivesse mantido as plantas por menos tempo nesses recipientes (Ronchi et al., 2006).

A redução do crescimento da parte aérea, em função da restrição ao crescimento radicular, decorre, principalmente, da aclimatação da maquinaria fotossintética, por um processo denominado retroinibição da fotossintese (Stit, 1991; Ronchi et al., 2006; Macana, 2012). Em essência, a redução da força do dreno, associada ao elevado grau de restrição radicular, ocasiona o acúmulo de carboidratos nas células mesofilicas da folha-fonte, aumentando a relação fonte:dreno. Isso reduz as taxas de assimilação líquida de carbono e, desse modo, o crescimento da parte aérea. Não obstante, outros processos fisiológicos podem ser igualmente afetados pelo tamanho do vaso reduzido, como, por exemplo, a absorção de água e nutrientes (Andrade et al., 2012).

Em mudas de Carapa guianensis, Lunz et al. (2011) observaram que a restrição do crescimento do sistema radicular, proporcionada pelo volume reduzido do recipiente, promoveu o desequilíbrio na razão entre raízes e parte aérea, alterando as respostas fisiológicas da planta e repercutindo na sua qualidade. Em café, Ronchi et al. (2006) demonstraram que a taxa de assimilação líquida de carbono (e por conseguinte o crescimento das plantas) foi reduzida quando as plantas foram cultivadas em recipientes pequenos, devido a fatores não estomáticos, como a comprovada redução na atividade carboxilativa da Rubisco. Estes autores também demonstraram, para espécie como o café, que o tempo de permanência da planta no vaso é um fator imprescindivel a ser levado em consideração no momento da escolha do tamanho do vaso de cultivo.

Na área da Ciência das Plantas Daninhas, por exemplo, é muito comum a realização de experimentos em vasos para avaliar a competição entre plantas, eficácia de herbicidas, seletividade de herbicidas para diferentes genótipos, curvas dose-resposta, entre outros (Ferreira et al., 2006; Santos et al., 2006; Ruas et al., 2012). Nestes ou em qualquer ensaio com plantas em vasos, considerando-se que eles não tenham sido adequadamente dimensionados à espécie e ao tempo de cultivo (periodo experimental), pode-se supor que as respostas obtidas estejam parcialmente condicionadas ao tamanho do vaso e não aos tratamentos per se.

Considerando-se que há alteração da relação fonte:dreno pelo cultivo, por determinado tempo, de plantas de Brachiaria decumbens em vasos de diferentes tamanhos, e que isso altera o crescimento e a morfologia tanto do sistema radicular como da parte aérea dessa espécie, testou-se a hipótese de que e eficácia de controle da planta daninha, obtida com a aplicação de diferentes doses de glyphosate, é dependente do tamanho de vaso utilizado no 
cultivo dessa planta. O objetivo deste trabalho foi avaliar a interação entre o tamanho do vaso de cultivo e doses de glyphosate no crescimento, na fisiologia e na eficácia de controle de $B$. decumbens.

\section{MATERIAL E MÉTODOS}

O experimento foi conduzido em casa de vegetação, utilizando-se como substrato uma mistura de solo, areia e esterco bovino, na proporção de $3: 1: 1(\mathrm{v} / \mathrm{v} / \mathrm{v})$, adubado com $0,5 \mathrm{~kg} \mathrm{~m}^{-3}$ de $\mathrm{K}_{2} \mathrm{O}$ e $5 \mathrm{~kg} \mathrm{~m}^{-3}$ de $\mathrm{P}_{2} \mathrm{O}_{5}$. O substrato foi peneirado, para facilitar a sua remoção durante a lavagem das raízes, eliminando-se materiais grosseiros. Utilizaram-se vasos de polietileno de diferentes volumes: 2, 5, 10 e 20 L. Para cada tamanho foram utilizados 20 vasos, totalizando 80 vasos.

Semearam-se 30 sementes de Brachiaria decumbens por vaso, em 20/09/2013, e, aos 20 dias após a semeadura, foi realizado o desbaste, deixando-se 13 plantas por vaso. Foram adicionados em cada vaso, aos 27,43 e 59 dias após a semeadura, $100 \mathrm{~mL}$ de uma solução contendo sulfato de amônio na concentração de $10 \mathrm{~g} \mathrm{~L}^{-1}$. A irrigação nos vasos foi realizada diariamente e mais de uma vez por dia, quando necessário, através de regador, de maneira que não permitisse o encharcamento ou a lixiviação de nutrientes.

O experimento foi realizado em duas etapas: na primeira, foi feita a caracterização do crescimento das plantas de $B$. decumbens em função dos diferentes tamanhos de vasos - etapa denominada "antes da aplicação do herbicida". Na segunda etapa, foram avaliadas as respostas das plantas de $B$. decumbens, cultivadas nos diferentes tamanhos de vasos, a quatro doses de glyphosate - etapa denominada "após a aplicação do herbicida". Antes da aplicação do herbicida, considerou-se o delineamento inteiramente casualizado, com quatro tratamentos e 20 repetições; após a aplicação do herbicida, passou-se a um delineamento em blocos ao acaso com quatro repetições, com 16 tratamentos dispostos em arranjo fatorial $4 \times 4$ (quatro tamanhos de vaso e quatro doses de glyphosate).

Nos 80 vasos foram feitas medições de crescimento das plantas de $B$. decumbens: aos 41 dias pós a emergência (DAE) contou-se o número de perfilhos por vaso; e aos $48 \mathrm{DAE}$, mediram-se o comprimento e a largura das folhas de três perfilhos por vaso, para estimativa da área foliar média do perfilho e estimativa da área foliar (AF) total do vaso, utilizando-se da equação: $\mathrm{AF}=0,9810 \times$ (comprimento x largura), correspondendo a $98,10 \%$ do produto entre o comprimento da nervura principal e a largura máxima (Bianco et al., 2000).

Aos 63 DAE, em 16 dos 80 vasos iniciais, realizaram-se as seguintes medições destrutivas, em cada tamanho de vaso: matéria seca da parte área (constituída do colmo e das folhas), matéria seca de raízes, matéria seca da planta inteira e volume de raízes. As raízes foram lavadas em água corrente, em peneiras de $3 \mathrm{~mm}$. Em seguida, todo o material (parte aérea e raízes) foi seco em estufa de circulação forçada de ar por $72 \mathrm{~h}$ a $70{ }^{\circ} \mathrm{C}$. Na medição do volume das raízes utilizou-se uma proveta de $500 \mathrm{~mL}$, determinando-se o volume de líquido deslocado após imersão do sistema radicular. Estimaram-se ainda a relação raiz: parte aérea e a razão de área foliar (relação entre a área foliar total e a matéria seca total da planta).

Aos 64 DAE foi realizada a aplicação do herbicida glyphosate (sal de isopropilamina de $\mathrm{N}$ - (fosfonometil) glicina, $360 \mathrm{~g} \mathrm{~L}^{-1}$ de equivalente ácido), utilizando um pulverizador costal pressurizado a $\mathrm{CO}_{2}$, trabalhando à pressão constante de $3,0 \mathrm{kgf} \mathrm{cm}^{-2}$, equipado com barra para duas pontas de jato tipo leque (Teejet XR 110.03), espaçadas de 0,50 m entre $\mathrm{si}$, a $0,50 \mathrm{~m}$ do alvo, com velocidade de $7,2 \mathrm{~km} \mathrm{~h}^{-1}$, aplicando-se o volume equivalente a $200 \mathrm{~L} \mathrm{ha}^{-1}$ de calda. Os dados climáticos do dia da aplicação foram: velocidade do vento de $2,38 \mathrm{~km} \mathrm{~h}^{-1}$, umidade relativa do ar de $78 \%$ e temperatura do ar de $24{ }^{\circ} \mathrm{C}$. As doses utilizadas foram: 0,0, 0,8, 1,6 e 3,2 $\mathrm{kg} \mathrm{ha}^{-1}$ e.a.

No segundo dia após a aplicação (DAA) dos herbicidas, realizaram-se avaliações instantâneas de trocas gasosas, entre 8 e 10h, na porção mediana da segunda folha completamente desenvolvida a partir do ápice de um dos perfilhos. Foi utilizado analisador de gases no infravermelho - IRGA, modelo LiCor 6400 XT, em sistema aberto, luz saturante artificial de $1.500 \mu \mathrm{mol}$ fótons $\mathrm{m}^{-2} \mathrm{~s}^{-1} \mathrm{e}$ concentração ambiente de $\mathrm{CO}_{2}$. Foram determinadas a taxa de 
assimilação líquida de $\mathrm{CO}_{2}(A)$, condutância estomática $\left(g_{\mathrm{s}}\right)$ e taxa transpiratória $(E)$. Ao longo da avaliação, a umidade do ar foi de $44,28 \%$, com temperatura do ar de $28,12{ }^{\circ} \mathrm{C}$, temperatura da folha de $28,50{ }^{\circ} \mathrm{C}$ e diferença de pressão de vapor entre o interior da folha e a atmosfera de $2,21 \mathrm{kPa}$.

Simultaneamente à medição das trocas gasosas, foram estimados os parâmetros de fluorescência da clorofila $a$ em folhas adaptadas à luz: $\phi_{\text {FSII }}$ - máximo rendimento quântico do transporte de elétrons; $F_{\mathrm{v}}{ }^{\prime} / F_{\mathrm{m}}{ }^{\text {' }}$ - eficiência de transferência de energia de excitação através do fotossistema II (FSII); e qP - quenching fotoquímico (Baker \& Rosenqvist, 2004).

Aos $7,14,21$ e 28 DAA, realizaram-se avaliações visuais da porcentagem de controle, conforme metodologia proposta pela Asociación Latinoamericana de Malezas (ALAM, 1974). Aos 28 DAA, a parte aérea presente nos vasos foi seccionada próxima ao solo e seca em estufa de circulação forçada de ar por $72 \mathrm{~h}$, a $70^{\circ} \mathrm{C}$, e, em seguida, pesada, para determinação da matéria seca da parte aérea após aplicação do herbicida. Após o corte da parte aérea, os vasos foram periodicamente irrigados para permitir a eventual rebrota. Assim, 28 dias depois, as plantas que rebrotaram foram seccionadas próximo ao solo e secas em estufa em iguais condições, sendo posteriormente pesadas, para determinação da matéria seca da rebrota.

Para as análises estatísticas, utilizou-se o software Saeg ${ }^{\circledR}$ (Saeg, 2009), e para confecção dos gráficos, o SigmaPlot ${ }^{\circledR}$ (SigmaPlot, 2008). Ajustaram-se equações de regressão, relacionando cada variável com o tamanho de vaso de cultivo ou com as doses de glyphosate; em casos de interação significativa, ajustaram-se superficies de respostas, relacionando cada variável simultaneamente aos dois fatores investigados. Em ambos os casos, escolheram-se equações com alto $\mathrm{R}^{2}$ e que, simultaneamente, descrevessem o fenômeno biológico.

\section{RESULTADOS E DISCUSSÃO}

Houve influência significativa $(\mathrm{p} \leq 0,05)$ do tamanho do vaso sobre o crescimento de B. decumbens. Com o aumento do tamanho do vaso, verificou-se aumento linear do número de perfilhos por vaso, da área foliar por perfilho e, consequentemente, da área foliar por planta e da área foliar por vaso (Figura 1 A-D).
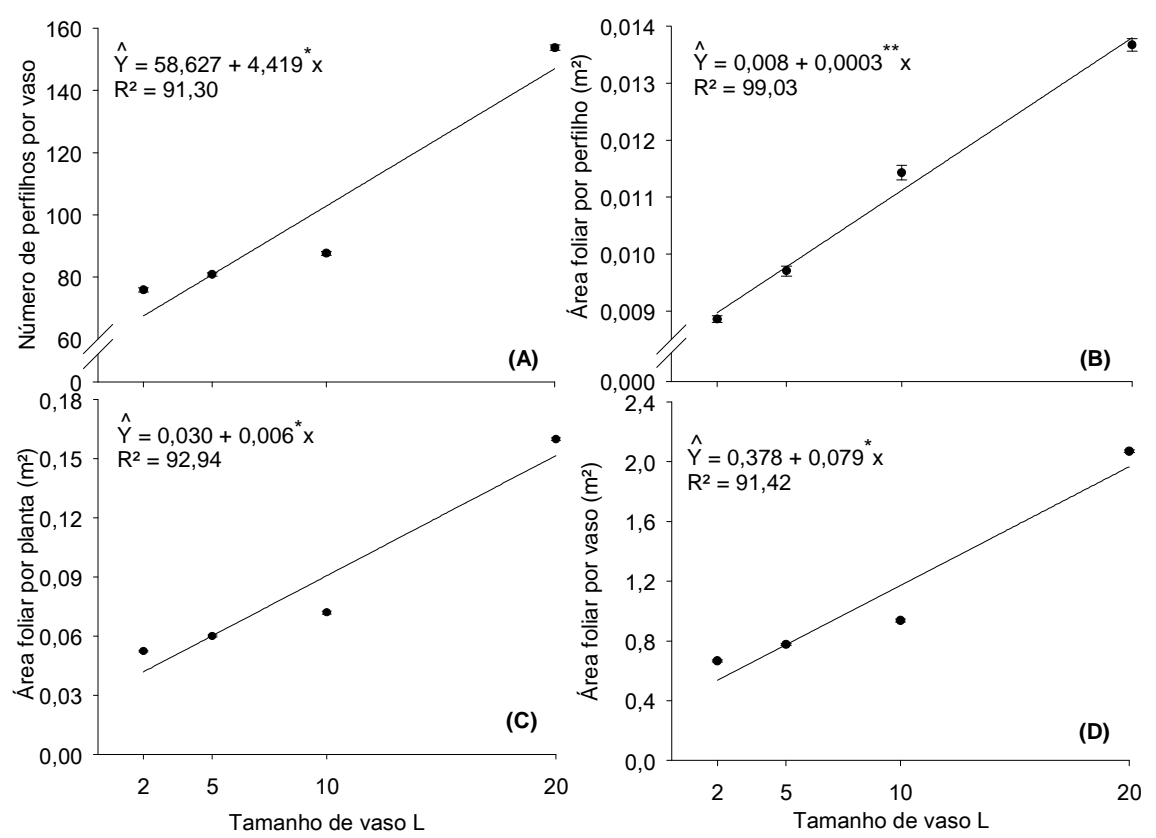

*, ** Significativo a 5 e $1 \%$, respectivamente, pelo teste t. A dispersão dos pontos refere-se à média \pm erro-padrão da média.

Figura 1 - Crescimento da braquiária em função do tamanho de vaso. Número de perfilhos por vaso (A), área foliar por perfilho (B), área foliar por planta (C) e área foliar por vaso (D). 
Observaram-se, também, acréscimos $(\mathrm{p} \leq 0,05)$ do volume de raízes por vaso (Figura 2A), da matéria seca das raízes por vaso (Figura 2B), da matéria seca da parte aérea por vaso (Figura 2C), da matéria seca por planta (Figura 2D) e da razão de área foliar (Figura 2E).

Essa resposta positiva no crescimento das plantas, com aumento do tamanho do vaso, ocorreu devido ao maior desenvolvimento das raizes, pelo maior volume de solo explorado, como observado por Almeida et al. (2014), trabalhando com Bidens pilosa, e Lunz et al. (2011), com mudas de Carapa guianensis. Os vasos de pequeno volume reduzem a eficiência de absorção de água e nutrientes, ocasionada pelo pequeno volume de raízes, além das possiveis modificações anatômicas ou morfológicas do sistema radicular e, principalmente, retroinibição da fotossíntese pela redução da força do dreno, com consequente aumento da relação fonte:dreno (Ronchi et al., 2006). Isso promove redução no crescimento da parte aérea mais intensa que no crescimento radicular, de forma que o resultado é o aumento na razão raiz:parte aérea, com a redução do tamanho do vaso, conforme pode ser observado nas Figuras 2 e 3F.
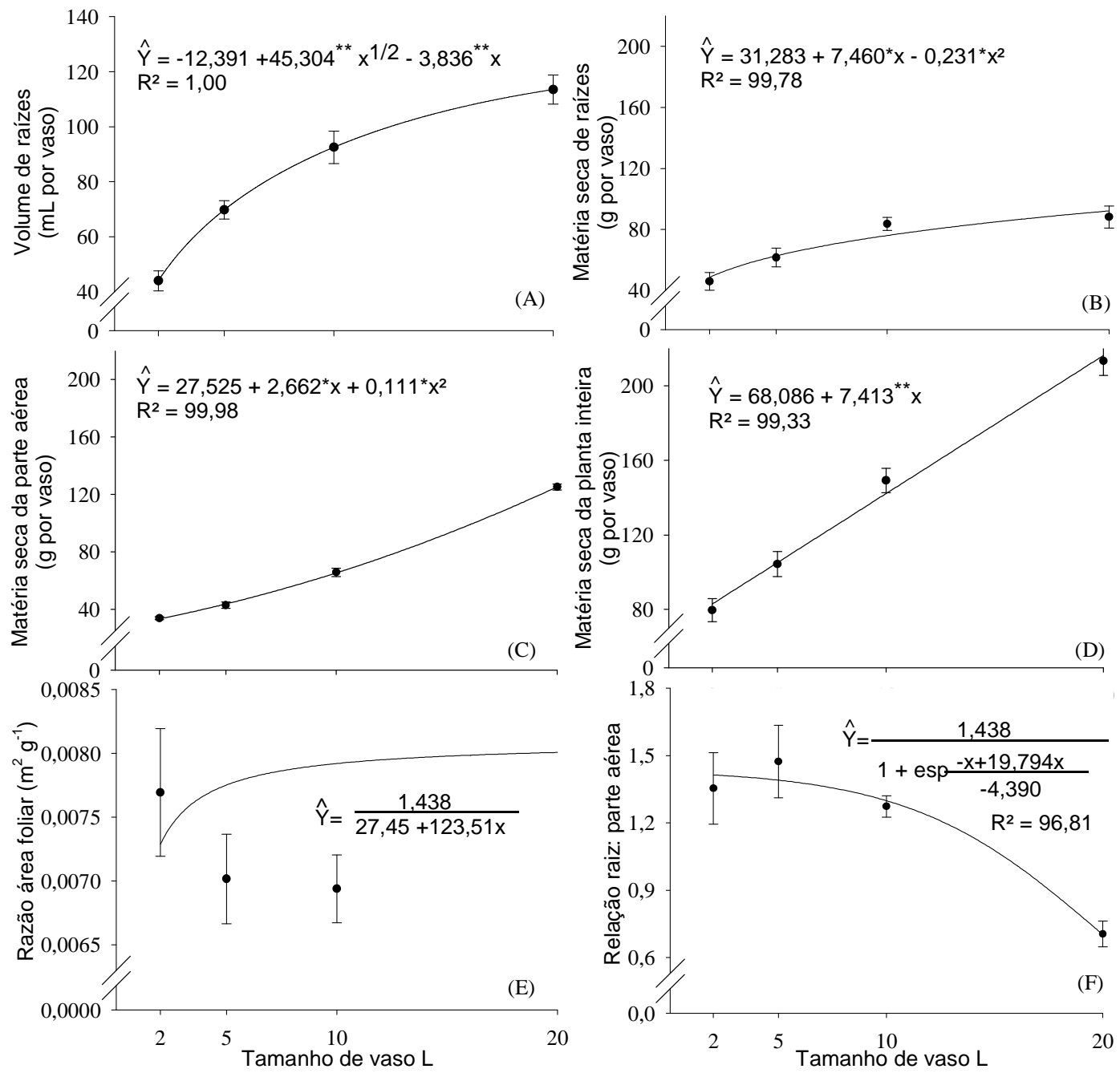

*,** significativo a 5 e $1 \%$ de probabilidade, respectivamente, pelo teste $t$.

Figura 2 - Crescimento da parte aérea e de raízes de braquiária em função do tamanho do vaso de cultivo. Volume (A) e matéria seca (B) de raízes por vaso, matéria seca da parte aérea (C) e da planta inteira (D) por vaso, razão de área foliar (E) e razão raiz: parte aérea $(F)$. 


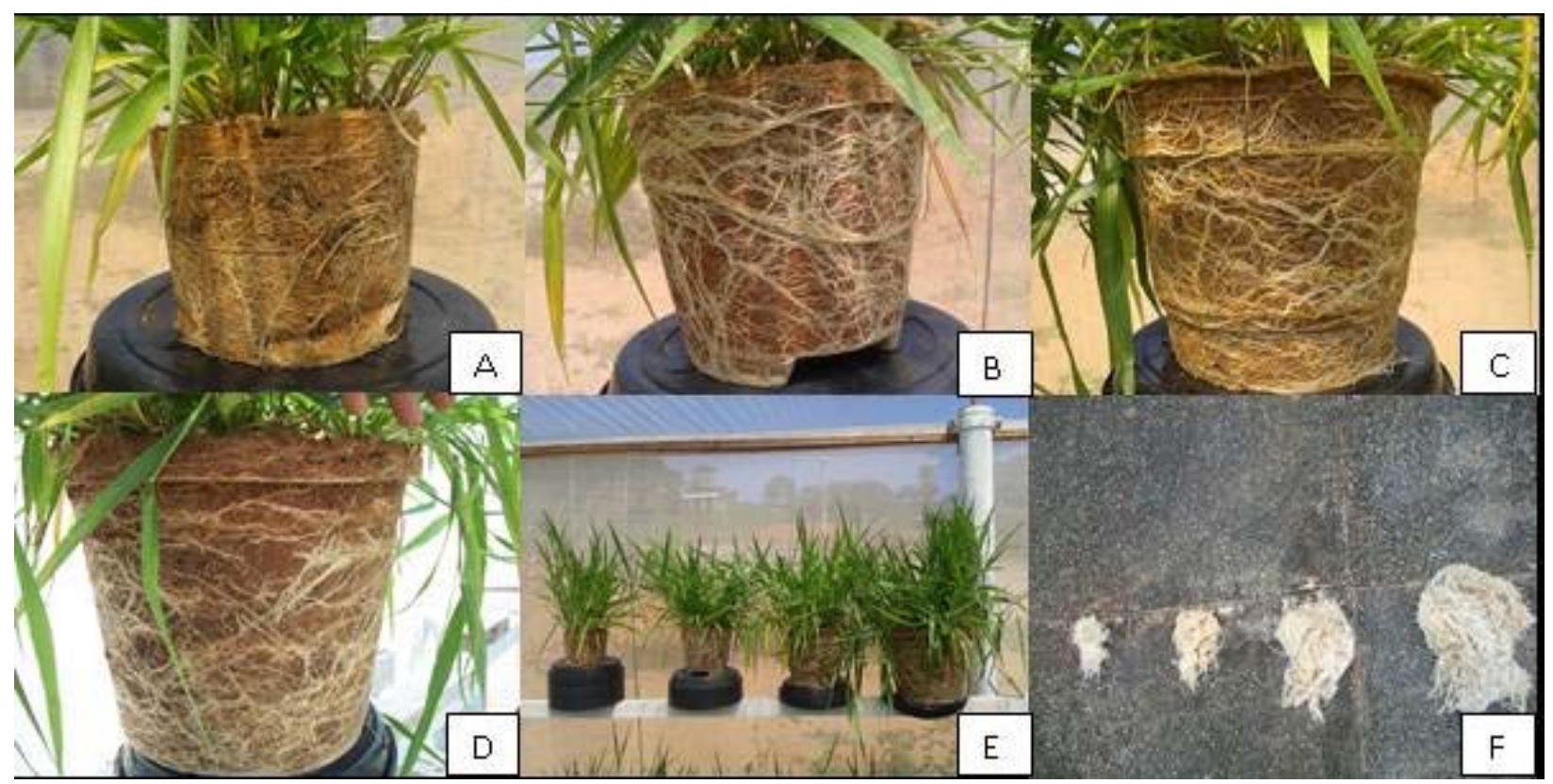

Figura 3 - Sistema radicular de B. decumbens cultivada em vasos de 2 (A), 5 (B), 10 (C) e 20 L (D). Nas Figuras E e F são apresentadas, respectivamente, a parte aérea e o sistema radicular das plantas nos quatro tamanhos de vasos, do menor (esquerda) para o maior (direita).

Efeitos da restrição do crescimento radicular no crescimento de plantas também foram relatados para outras espécies. Santos et al. (2012), por exemplo, observaram que o volume do recipiente contribuiu de forma determinante para a distribuição espacial das raízes de Passiflora cincinnata, uma vez que constataram menor comprimento de sistema radicular das plantas no recipiente de menor volume, o que provocou enraizamento reduzido. Santos et al. (2000) relatam que mudas de Cryptomeria japonica mostraram maior crescimento quando produzidas em recipientes (tubetes) de maior volume, independentemente do substrato utilizado. Andrade et al. (2012) relataram, em trabalho com mamona, que o recipiente de maior capacidade proporcionou maior volume de solo a ser explorado pelo sistema radicular, aumentando a absorção de água e nutrientes, a taxa de fotossintese e, consequentemente, promovendo maior desenvolvimento da parte aérea. Todavia, Oliveira (2011) não verificou diferenças no desenvolvimento das plantas de Copernicia hospita quando cultivadas nos diferentes tamanhos de recipientes: $20 \times 30$, $28 \times 40$ e $40 \times 60 \mathrm{~cm}$.

Aos dois dias após a aplicação dos herbicidas, não se verificou efeito significativo $(p>0,05)$ da interação entre tamanho do vaso e doses de herbicidas, nem do tamanho de vaso, independentemente da dose, sobre as trocas gasosas, avaliadas pela taxa de assimilação líquida de $\mathrm{CO}_{2}(A)$, condutância estomática $\left(g_{\mathrm{s}}\right)$ e taxa transpiratória $(E)$, e sobre os parâmetros de fluorescência da clorofila $a$ (Tabela 1). Todavia, observou-se significância $(\mathrm{p} \leq 0,05)$ da dose de glyphosate sobre $A, g_{\mathrm{s}} \mathrm{e}$ $E$, que reduziram com o aumento da dose de glyphosate (Figura $5 \mathrm{~A}-\mathrm{C}$ ), apresentando decaída exponencial do tratamento controle para aquele com a menor dose de glyphosate. Isso indica que até as doses menores que as recomendadas para controle de $B$. decumbens interferem severamente nas trocas gasosas dessa planta daninha.

Os valores máximos das taxas de assimilação líquida do carbono $(A)$, nas plantas de $B$. decumbens não tratadas com herbicida, foram, de modo geral, inferiores aos encontrados em outras espécies do mesmo gênero, como $B$. brizantha e $B$. humidicola cultivadas em vasos, em ambiente protegido e, ou, sombreado (Dias-Filho, 2002). Foram inferiores também àqueles obtidos por Ruas et al. (2011), em plantas de $B$. decumbens cultivadas em vasos de $11 \mathrm{~L}$, em condições semelhantes às 
Tabela 1 - Trocas gasosas e parâmetros de fluorescência da clorofila $a$ em função de diferentes tamanhos de vaso, independentemente de doses de herbicida. Taxa de assimilação líquida de $\mathrm{CO}_{2}(A)$, condutância estomática $\left(g_{\mathrm{s}}\right)$, taxa transpiratória $(E)$, máximo rendimento quântico do transporte de elétrons $\left(\phi_{\mathrm{FSII}}\right)$, eficiência de transferência de energia de excitação através do FSII $\left(F_{\mathrm{v}}\right.$ ' $\left./ F_{\mathrm{m}}{ }^{\prime}\right)$ e quenching fotoquímico $(q \mathrm{P})$. (médias \pm erro-padrão da média)

\begin{tabular}{|c|c|c|c|r|}
\hline \multirow{2}{*}{ Parâmetro } & \multicolumn{5}{|c|}{ Tamanho de vaso (L) } \\
\cline { 2 - 5 } & 2 & 5 & 10 & 20 \\
\hline \multicolumn{5}{|c|}{ Trocas gasosas } \\
\hline$A$ & $6,18 \pm 0,31$ & $5,76 \pm 0,34$ & $3,76 \pm 0,32$ & $5,77 \pm 0,41$ \\
\hline$g_{\mathrm{s}}$ & $30,94 \pm 1,21$ & $31,59 \pm 1,45$ & $25,31 \pm 1,05$ & $0,81 \pm 0,05$ \\
\hline$E$ & $0,74 \pm 0,03$ & $0,79 \pm 0,04$ & $0,62 \pm 0,03$ & $0,417 \pm 0,006$ \\
\hline \multicolumn{5}{|c|}{ Fluorescência } \\
\hline$F_{\mathrm{v}} / F_{\mathrm{m}}$ & $0,417 \pm 0,004$ & $0,381 \pm 0,005$ & $0,379 \pm 0,006$ & $0,181 \pm 0,005$ \\
\hline$q P$ & $0,171 \pm 0,003$ & $0,196 \pm 0,004$ & $0,155 \pm 0,005$ & $0,078 \pm 0,003$ \\
\hline$\phi_{\mathrm{FSII}}$ & $0,072 \pm 0,002$ & $0,077 \pm 0,002$ & $0,061 \pm 2,303$ & \\
\hline
\end{tabular}

deste experimento. Essas diferenças se devem provavelmente ao maior tempo em que as plantas de $B$. decumbens permaneceram nos vasos até o momento da aplicação, pois no trabalho de Ruas et al. (2011) a aplicação foi feita aos 45 DAE e, no presente experimento, apenas aos $64 \mathrm{DAE}$. Isso evidencia que o tempo de cultivo exerce influência no crescimento radicular, alterando a relação fonte:dreno, promovendo aclimatação fotossintética, como demonstrado para o café (Ronchi et al., 2006).

Dificilmente ocorreram reduções nos níveis foliares de clorofila capazes de causar reduções em $A$, evento comum em plantas tratadas com glyphosate (Kitchen et al., 1981; Lee, 1981; Hess \& Bridges, 2000), uma vez que havia transcorrido apenas $48 \mathrm{~h}$ da aplicação e nenhum sintoma de clorose existia na folha. As reduções observadas em $A$ nas folhas de plantas tratadas com glyphosate (Figura 4B) podem, em parte, ser atribuídas a limitações estomáticas da fotossíntese, uma vez que quedas significativas ocorreram em $g_{\mathrm{s}}$ (Figura 4A). Entretanto, reduções na condutância estomática não alteraram a razão $\mathrm{Ci} / \mathrm{C}_{\mathrm{a}}$ entre os tratamentos, sugerindo que limitações não estomáticas, provavelmente, também comprometeram as taxas de assimilação do carbono.

Em razão da inibição da EPSPs, a biossíntese de triptofano, fenilalanina e tirosina é paralisada e, por conseguinte, a sintese de proteínas e de outros compostos aromáticos tão necessários ao crescimento do tecido vegetal. No entanto, a desregulação da rota do ácido chiquímico leva a uma perda significativa (muito superior a 20\%) dos carbonos do ciclo de Calvin, o que compromete a fotossintese. Uma vez inibida a EPSPs, há acúmulo acentuado nos niveis de chiquimato, levando a duas consequências: a) consumo acelerado de eritrose-4-P, composto carbônico intermediário na fase de regeneração da RuBP (ribulose-1,5bisfosfato, aceptor de $\mathrm{CO}_{2}$ na fase de carboxilação do ciclo de Calvin); e b) exaustão dos niveis de PEP (fosfoenolpiruvato, aceptor de $\mathrm{CO}_{2}$ em plantas $\mathrm{C}_{4}$ ) na célula (Hess \& Bridges, 2000; Taiz \& Zeiger, 2009). Consequentemente, a etapa bioquímica da fotossíntese foi limitada em folhas de $B$. decumbens, planta $\mathrm{C}_{4}$, pela ação do glyphosate, explicando, pelo menos em parte, as quedas observadas em $A$, dois dias após tratamento das plantas com glyphosate.

É importante registrar que as folhas de plantas de $B$. decumbens tratadas com o herbicida apresentaram baixa capacidade fotoquímica na utilização dos fótons absorvidos para assimilação do $\mathrm{CO}_{2}$, e esse efeito foi mais intenso com o aumento das doses (Figura 5). Isso ocorreu porque, sob efeito do herbicida, as reduções tanto na eficiência de captura de energia de excitação pelos centros de reação abertos do FSII $\left(F_{\mathrm{v}}^{\prime} / F_{\mathrm{m}}{ }^{\prime}\right.$ - Figura $\left.5 \mathrm{~A}\right)$, como na proporção de centro de reações abertos do FSII ( $q \mathrm{P}$ - Figura 5B), ocasionaram, em conjunto, reduções drásticas no rendimento quântico do transporte de elétrons através do FSII $\left(\phi_{\mathrm{FSI}}-\right.$ Figura 5C) (Baker \& Rosenqvist, 2004). Tomados em conjunto, todos esses resultados também explicam o comprometimento do processo fotossintético na presença do glyphosate. 
Não houve efeito significativo da interação entre tamanho de vaso e doses de glyphosate para a porcentagem de controle, em nenhuma das épocas de avaliação. Verificou-se, entretanto, que ocorreu efeito significativo do tamanho de vaso sobre a eficácia de controle aos 7 e 14 DAA (Figura $6 \mathrm{~A}$ e B): houve redução da porcentagem de

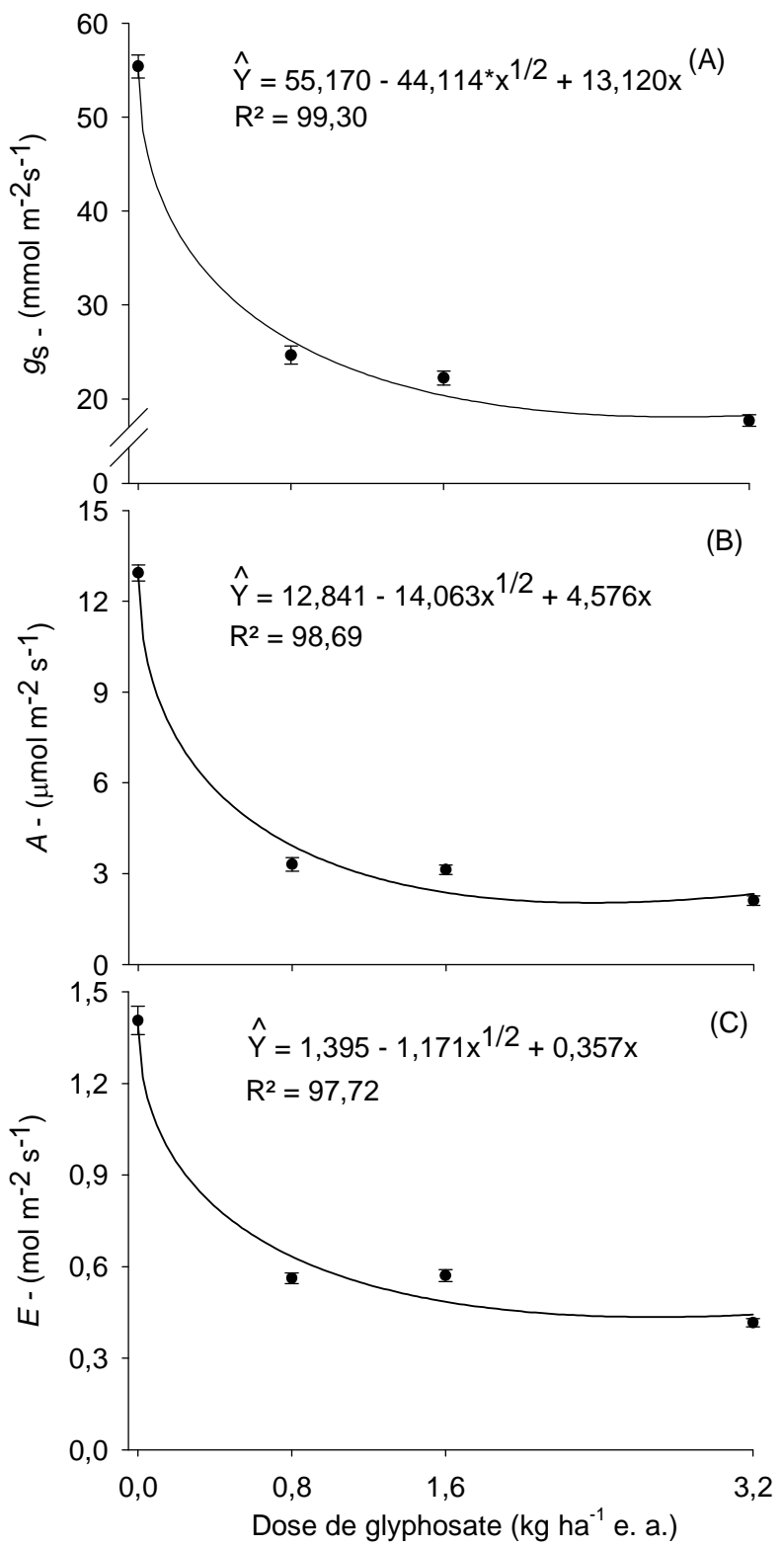

Figura 4 - Trocas gasosas em folhas de braquiária, em função de diferentes doses de glyphosate, independentemente do tamanho de vaso: condutância estomática - $g_{\mathrm{s}}(\mathrm{A})$; taxa de assimilação líquida de $\mathrm{CO}_{2}$ - $A$ (B); e taxa transpiratória $E(\mathrm{C})$. controle com a redução do tamanho de vaso. Aos 21 e 28 DAA esse efeito não foi observado (Figura 6C e D). Quanto à porcentagem de controle, em todas as épocas avaliadas, ela aumentou $(p<0,05)$ com o aumento da dose do herbicida (Figura 6E, F, G e H), seguindo um modelo logístico, independentemente do tamanho de vaso.

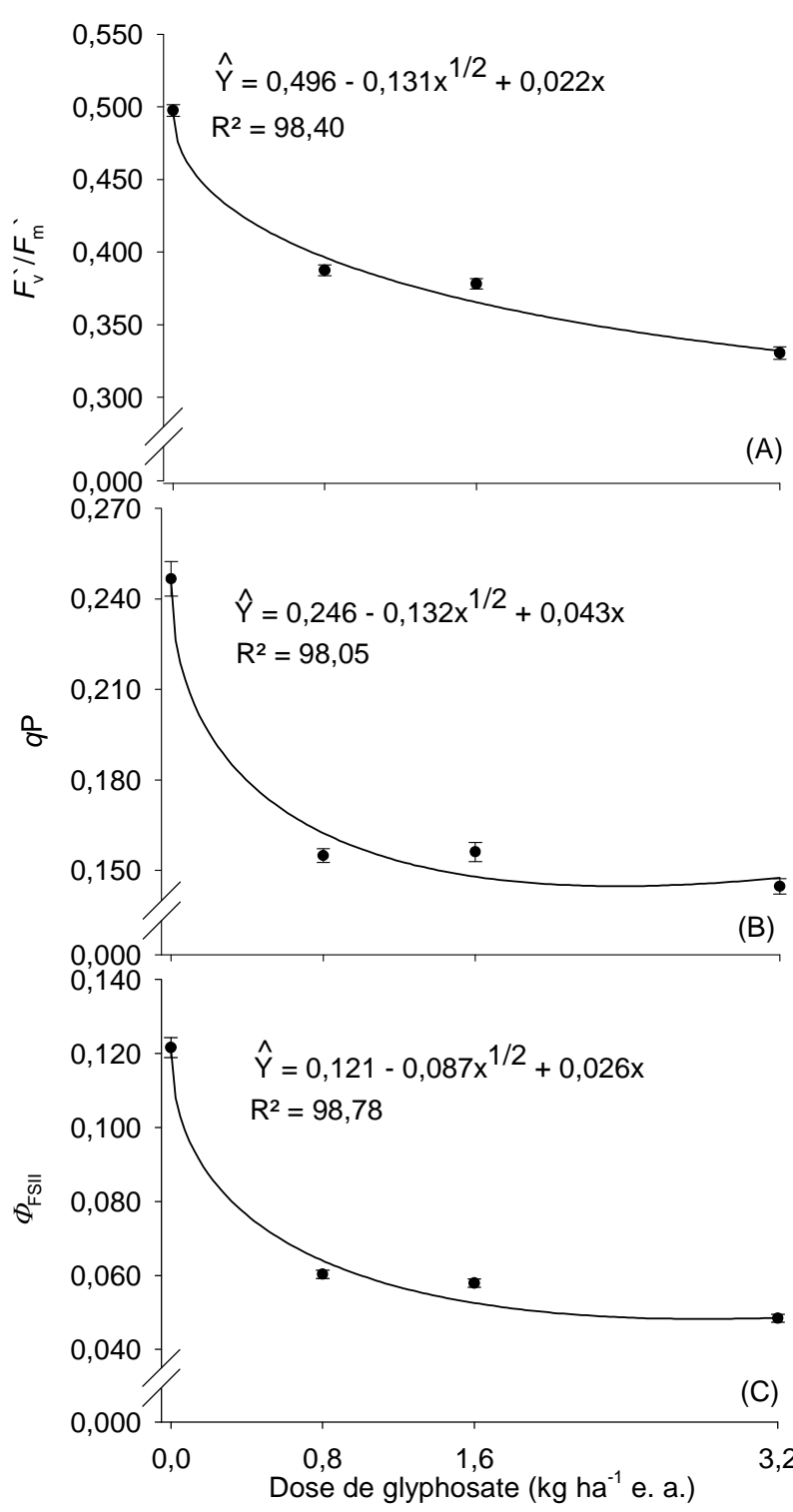

Figura 5 - Respostas dos parâmetros de fluorescência da clorofila $a$ às doses de glyphosate. Eficiência de transferência de energia de excitação através do FSII - $F_{\mathrm{v}}$ ' $/ F_{\mathrm{m}}$ ' $(\mathrm{A})$; quenching fotoquímico - $q \mathrm{P}$ (B); e máximo rendimento quântico do transporte de elétrons $\phi_{\mathrm{FSII}}(\mathrm{C})$. 


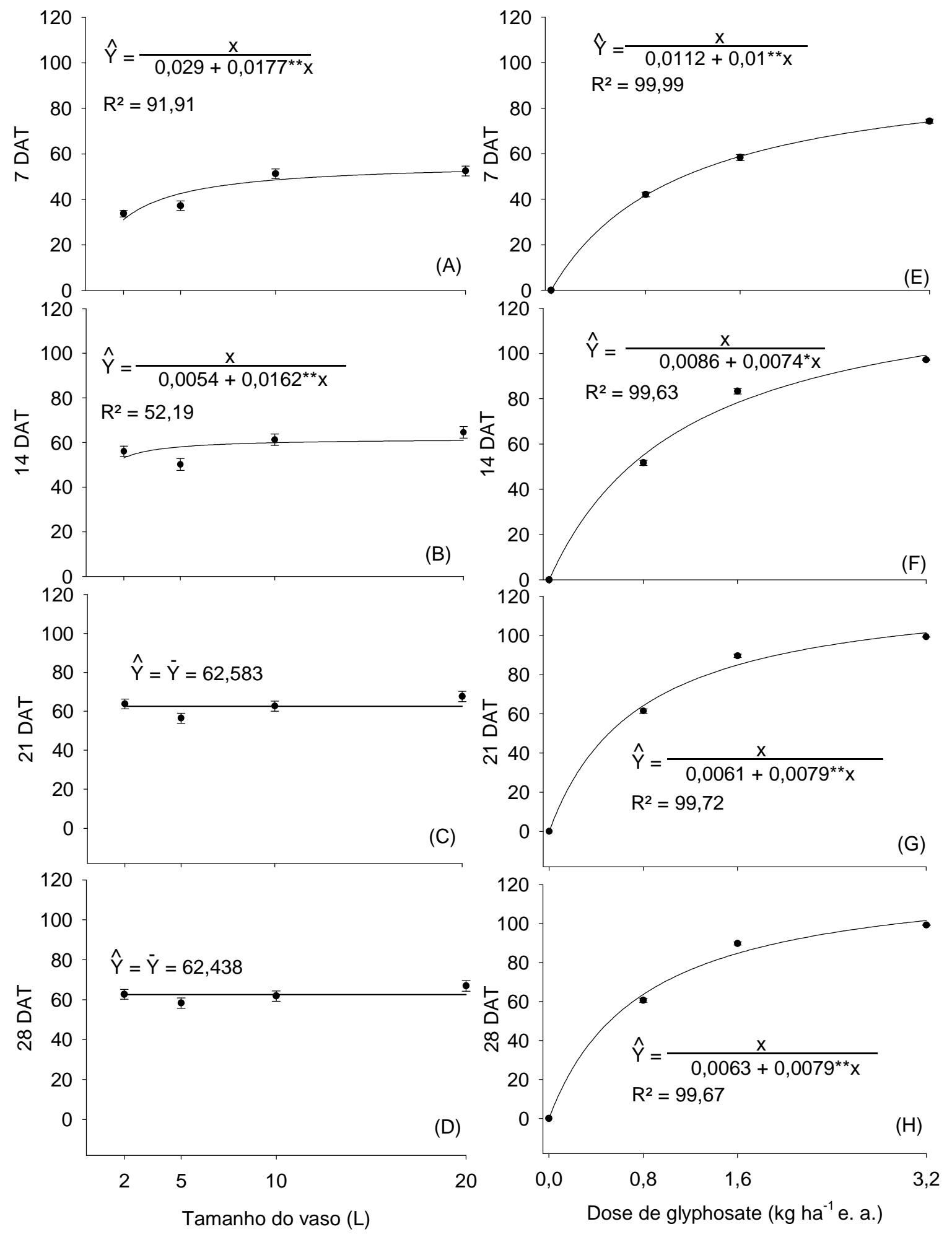

*,** significativo a 5 e $1 \%$ de probabilidade, respectivamente, pelo teste t.

Figura 6 - Porcentagem de controle de B. decumbens aos 7, 14, 21 e 28 dias após aplicação dos tratamentos - DAT, em função do tamanho do vaso (esquerda) e de doses de glyphosate (direita). 
Devido à natureza sistêmica do glyphosate e ao seu mecanismo de ação, o efeito sobre as plantas daninhas é lento e a cobertura demora alguns dias para morrer completamente (Constantin et al., 2008). Em função da elevada restrição ao crescimento radicular (alta razão raiz: parte aérea, Figura $2 \mathrm{~F}$ ) nos vasos de menor volume, e à consequente menor força do dreno, a translocação de herbicida ao seu sítio de ação foi provavelmente comprometida a ponto de retardar seu efeito fitotóxico (dessecação mais lenta, para uma mesma dose). Isso comprova, portanto, um leve efeito do tamanho de vaso sobre a eficácia do herbicida avaliada na primeira quinzena após sua aplicação.

A interação do tamanho do vaso com a dose de glyphosate foi significativa para a matéria seca da parte aérea por vaso, tomada aos 28 dias, ou seja, ela aumentou simultaneamente com a redução da dose e com o aumento do tamanho do vaso (Figura 7A). A mesma resposta foi observada para a matéria seca de rebrota por vaso (Figura 7B). Assim, sob doses elevadas de glyphosate, a eficácia do herbicida foi pouco ou levemente afetada pelo tamanho do vaso; contudo, sob doses mais reduzidas, o tamanho do vaso determinou a magnitude da resposta de controle. O aumento acentuado da matéria seca da planta inteira, com o aumento do tamanho do vaso (Figura 2D), provavelmente reduziu intensamente a concentração interna de glyphosate (efeito de diluição) nessas plantas, comprometendo o efeito final, mesmo a despeito de uma maior área foliar (maior superfície de absorção) das plantas dos vasos maiores (Figura 1D). Esses resultados são muito importantes, visto que demonstram claramente que as respostas acerca da eficácia de controle de $B$. decumbens com glyphosate foram dependentes não apenas da dose, mas também da interação da dose com o tamanho de vaso.

Para o efeito apenas de doses, resultados semelhantes foram encontrados por Constantin et al. (2008), os quais observaram que as doses baixas de glyphosate proporcionaram maior rebrota de $B$. decumbens, levando a uma maior competição com a cultura do milho, enquanto as doses mais altas foram suficientes para controlar as plantas daninhas, não ocorrendo rebrotas e competição.
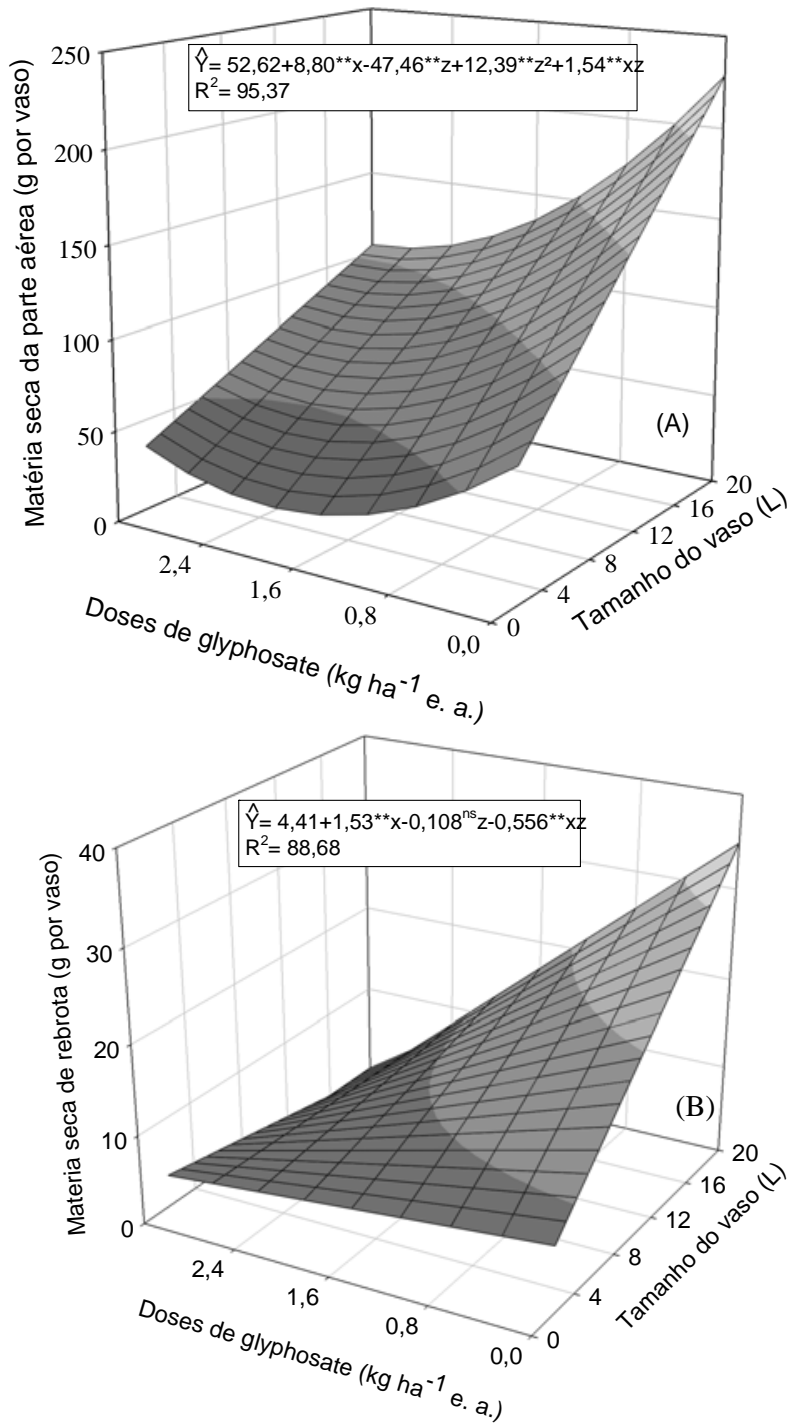

*,** significativo a 5 e $1 \%$ de probabilidade, respectivamente, pelo teste $\mathrm{t}$.

Figura 7 - Efeito da interação entre o tamanho do vaso e doses de glyphosate sobre a matéria seca da parte aérea por vaso, avaliado aos 28 dias após a aplicação (A), e a matéria seca de rebrota por vaso, aos 28 dias após o corte (B).

Esse mesmo resultado também foi verificado por Werlang et al. (2003) em plantas de $B$. decumbens; o melhor controle decorre da maior dose do herbicida, pois esta potencializa a quantidade absorvida, translocada e que alcança o local de ação, como era de se esperar para o comportamento desse herbicida na planta (Silva \& Silva, 2007). É importante registrar que em um sistema radicular mais desenvolvido, como o observado nas plantas dos 
vasos maiores (maior matéria seca; Figura 2B), há maior reserva de carboidratos, o que provavelmente potencializa a rebrota das plantas.

Tomados em conjunto, os resultados do presente trabalho evidenciaram que o tamanho do vaso de cultivo determina o crescimento da planta de $B$. decumbens, alterando sua relação fonte:dreno e, consequentemente, a resposta desta planta ao herbicida. Assim, é possivel concluir que a escolha correta do tamanho do vaso de cultivo é um passo decisivo para a realização e para o sucesso dos ensaios de eficácia de controle de $B$. decumbens com glyphosate (podendo, talvez, ser extrapolado para outras espécies e herbicidas sistêmicos), confirmando a hipótese inicial do presente trabalho.

\section{AGRADECIMENTOS}

Ao Conselho Nacional de Desenvolvimento Científico e Tecnológico (CNPq), pela concessão da bolsa de iniciação científica.

\section{LITERATURA CITADA}

ALMEIDA, M. O. et al. Influência do tamanho do vaso e época de avaliação sobre o crescimento do picão preto em competição com milho e soja. Biosci. J., v. 30, n. 5, p. 1428-1437, 2014.

ANDRADE, F. R. et al. Formação de mudas de mamona em diferentes recipientes. R. Bras. Ci. Agr., v. 7, n. 2, p. 274-279, 2012.

ASOCIACIÓN LATINO AMERICANA DE MALEZAS ALAM. Recomendaciones sobre unificación de los sistemas de evaluacion en ensayos de control de malezas. ALAM, v. 1, n. 1, p. 35-38, 1974.

BAKER, N. R.; ROSENQVIST, E. Applications of chlorophyll fluorescence can improve crop production strategies: an examination of future possibilities. J. Exper. Bot., v. 55, n. 403, p. 1607-1621, 2004.

BIANCO, S. et al. Estimativa da área foliar de plantas daninhas: Brachiaria decumbens Stapf. e Brachiaria brizantha (Hochst.) Stapf. Planta Daninha, v. 8, n. 1, p. 79-83, 2000.

CONSTANTIN, J. et al. Influência do glyphosate na dessecação de capim-braquiária e sobre o desenvolvimento inicial da cultura do milho. Planta Daninha, v. 26, n. 3, p. 627-636, 2008.
DIAS-FILHO, M. B. Photosynthetic light response of the $\mathrm{C}_{4}$ grasses Brachiaria brizanta and B. humidicola under shade. Sci. Agr., v. 59, n. 1, p. 65-68, 2002.

FERREIRA, E. A. et al. Glyphosate no controle de biótipos de azevém e impacto na microbiota do solo. Planta Daninha, v. 24 , n. 3, p. 573-578, 2006.

HESS, F. D.; BRIDGES, D. C. Inhibitors of aromatic amino acid biosynthesis (glyphosate). In: Herbicide action curse. West Lafayette: Purdue University, 2000. p. 452-466.

KITCHEN, L. M.; WITT, W. W.; RIECK, C. E. Inhibition of chlorophyll accumulation by glyphosate. Weed Sci., v. 29, n. 4, p. 513-516, 1981.

LEE, T. T. Effects of glyphosate on synthesis and degradation of chlorophyll in soybean and tobacco cells. Weed Res., v. 21, n. 3/4, p. 161-164, 1981.

LUNZ, A. M. P. et al. Produção de mudas de Carapa Guianensis Aubl. em diferentes tamanhos de recipientes, para uso em sistemas agroflorestais. In: CONGRESSO BRASILEIRO DE SISTEMAS AGROFLORESTAIS, 8., 2011, Belém. Anais... Belém: SBSAF: Embrapa Amazônia Oriental: UFRA: CEPLAC: EMATER: ICRAF, 2011. CD-ROM.

MACANA, Y. A. M. Efeitos da disponibilidade de água e de luz no metabolismo fotossintético em Coffea arabica. 2012. 46 f. Dissertação (Mestrado em Fisiologia Vegetal) Universidade Federal de Viçosa, Viçosa, 2012.

OLIVEIRA, A. B.; MEDEIROS FILHO, S.; BEZERRA, A. M. E. Tempo de cultivo e tamanho do recipiente na formação de mudas de Copernicia hospita. Acta Sci., v. 33, n. 3, p. 533-538, 2011.

RONCHI, C. P. et al. Growth and photosynthetic downregulation in Coffea arabica in response to restricted root volume. Funct. Plant Biol., v. 33, n. 11, p. 1013-1023, 2006.

RUAS, R. A. A. et al. Respostas fotossintéticas em plantas de braquiária submetidas a diferentes temperaturas de calda e doses de glyphosate. In: SIMPÓSIO INTERNACIONAL SOBRE GLYPHOSATE - USO SUSTENTÁVEL, 3., 2011, Botucatu. Anais... Botucatu: UNESP, 2011. p. 345-348.

RUAS, R. A. A. et al. Controle de Brachiaria decumbens Stapf com adição de ureia à calda do glifosato. Pesq. Agropec. Trop., v. 42, n. 4, p. 455-461, 2012.

SANTOS, J. F. et al. Propagação vegetativa de estacas de Passiflora cincinnata Mast. em diferentes recipientes e substratos comerciais. R. Bras. Frutic., v. 34, n. 2, p. 581-588, 2012.

SANTOS, M. V. et al. Controle de Brachiaria brizantha com uso do glyphosate após o estabelecimento de tifton 85 (Cynodon spp.). Planta Daninha, v. 24, n. 4, p. 813-819, 2006.

Planta Daninha, Viçosa-MG, v. 33, n. 4, p. 727-738, 2015 
SIGMAPLOT. 2008. For windows, version 11.0. Systat Software, 2008.

SANTOS, C. B. et al. Efeito do volume de tubetes e tipos de substratos na qualidade de mudas de Cryptomeria japonica (L. f.) D. Don. Ci. Flor., v. 10, n. 2, p. 1-15, 2000.

SILVA, A. A.; SILVA, J. F. Tópicos em manejo de plantas daninhas. Viçosa-MG: Universidade Federal de Viçosa, 2007. $367 \mathrm{p}$.

SISTEMA DE ANÁLISES ESTATÍSTICAS E GENÉTICAS - SAEG. versão 9.1. Viçosa, MG: Fundação Arthur

Bernardes, 2007.
STITT, M. Rising $\mathrm{CO}_{2}$ levels and their potential significance for carbon flow in photosynthetic cells. Plant Cell Environ., v. 14, p. 741-762, 1991.

TAIZ, L.; ZEIGER, E. Fisiologia vegetal. 4. ed. Porto Alegre: Artmed, 2009. 820 p.

VALLONE, H. S. et al. Efeito de recipientes e substratos utilizados na produção de mudas de cafeeiro no desenvolvimento inicial em casa de vegetação, sob estresse hídrico. Ci. Agrotec., v. 34, n. 2, p. 320-328, 2010.

WERLANG, R. C. et al. Efeitos da chuva na eficiência de formulações e doses de glyphosate no controle de Brachiaria decumbens. Planta Daninha, v. 21, n. 1, p. 121-130, 2003. 